\title{
Perancangan Simulator Programmable Logic Controller (PLC) untuk Praktikum
}

\author{
Muh Fikri S Nasir, M. Yunus Hi. Abbas, Idham A. Djufri \\ ${ }^{1}$ Fakultas Teknik \\ Program Studi Teknik Elektro \\ Universitas Khairun \\ Ternate, Indonesia
}

\begin{abstract}
Abstrak - Kegiatan praktikum merupakan salah satu faktor yang penting dalam menunjang keberhasilan mahasiswa dalam mengikuti proses kegiatan belajar mengajar dan untuk menunjang bahan praktikum dan menambah wawasan serta implementasi dari teori - teori yang dipelajari. Pembuatan simulator PLC menggunakan PLC omron CP1E 20 DRA dengan menggunakan sumber catu daya dan dengan menggunakan $\mathbf{C X}$ Programer sebagai aplikasi pembuatan Ladder Diagram sebagai pengatur input dan output pada PLC. Ladder diagram yang telah dibuat akan di transfer ke PLC untuk mengatur 4 aplikasi. Ada 4 percobaan yang didapkan dengan menggunakan PLC omron CP1E20 DRA yaitu pada percobaan gerbang logika dasar yaitu mampu menjalankan perintah NO, NC. Sedangkan pada pratikum PLC sederhana dengan tujuan mampu menjalankan perintah - perintah aplikasi PLC sederhana. Sedangkan pada percobaan tiga yaitu pada forward reverse control motor memiliki tujuan mampu membuat program untuk kendali motor dan pada percobaan aplikasi PLC lanjutan memiliki pembelajaran tentang timer dan control pada PLC.
\end{abstract}

Kata kunci: PLC, Simulator, Praktikum

\section{PENDAHULUAN}

Sejak ditemukannya Programmable Logic Controller (PLC) menurut Capiel pada tahun 1968, daya tahan ujinya sudah terbukti pada lingkungan perangkat keras dan telah dibuat untuk menangani banyak input dan output, dimana banyak pabrik-pabrik menggunakannya sebagai dasar untuk sistem automasi. Hal ini menjadikan PLC memiliki kemungkinan akan tetap menjadi paling utama untuk masa yang akan datang. PLC sendiri dapat dikombinasikan dengan sebagian besar teknologi yang menyediakan sistem control dan sistem pemantau.

Penerapan PLC meliputi berbagai jenis industri mulai dari industri rokok, otomotif, petrokimia, kertas, bahkan sampai pada industri tambang, misalnya pada pengendalian turbin gas dan unit industri lanjutan hasil pertambangan. Kemudahan transisi dari sistem kontrol sebelumnya (misalnya dari sistem kontrol berbasis relay mekanis) dan kemudahan trouble-shooting dalam konfigurasi sistem merupakan dua faktor utama yang mendorong populernya PLC ini. Kegiatan praktikum merupakan salah satu faktor yang penting dalam menunjang keberhasilan mahasiswa dalam mengikuti proses kegiatan belajar mengajar

Maka implementasi dalam pembelajaran teori juga sangat penting, akan tetapi keterbatasan alat yang juga menjadi suatu masalah dalam implentasi pembelajaran teori dengan adanya suatu alat untuk menambah pratikum sebagi implementasi teori juga penting karna hanya dengan teori belum cukup.

\section{TINJAUAN PUSTAKA}

Definisi Programmable Logic Controller adalah sistem elektronik yang beroperasi secara digital dan didisain untuk pemakaian di lingkungan industri [1]. Sistem ini menggunakan memori yang dapat diprogram untuk penyimpanan secara internal instruksi-instruksi yang mengimplementasikan fungsi-fungsi spesifik seperti logika, urutan, perwaktuan, pencacahan dan operasi aritmatik untuk mengontrol mesin atau proses melalui modul-modul I/O digital maupun analog.

Adapun berbagai macam peneltian yang dilakukan untuk membuat suatu simulasi PLC perancangan simulator PLC dengan menggunakan DELPHI Penelitian ini bertujuan untuk merancang sebuah Simulator PLC, yang dapat digunakan untuk memudahkan pengguna pemula memahami pemrograman dan cara kerja PLC. Pemrograman simulator PLC melalui IDE (Integrated Development Environment) dapat dilakukan untuk membuat program PLC mengunakan diagram Ladder dan Statement list 
(STL). Perintah-perintah dasar PLC, flag Timer, dan Counter dapat digunakan untuk pemrograman menggunakan Diagram Ladder [2]. Perancangan Simulasi Supervisory Control and Data Acquisition pada purwa rupa Sistem Listrik Redundant adalah suatu sistem yang mengumpulkan data dan menganalisisnya secara real time dengan menggunakan PLC dan sistem SCADA [3]

Dengan mengembangkan alat pratikum dasar otomasi industri modular dengan menggunakan PLC OMRON dengan tipe CP1L yang memiliki 12 terminal input dan 8 terminal output. PLC CP1L ini cukup sederhana dan sangat cocok untuk dijadikan perangkat latih sederhana untuk pembelajaran otomasi industri di perguruan tinggi [4]. Maka dengan metode eksperimen. Modul latihan menggunakan peralatan kontrol standar industri yaitu programmable logic controller dengan sistem control waktu nyata menggunakan perangkat lunak $C X$ Designer. Beberapa contoh aplikasi yang diterapkan pada modul latih ini adalah simulator Logika Dasar, Simulator Traffic light, dan Simulator Bel Kuis Priorita [5].

\section{METODOLOGI}

Metode penelitian yang digunakan dalam penelitian ini adalah lab experiment. Percobaan yang dilakukan didukung dengan literatur yang ada serta mengkombinasikan serta mengembangkan dari penelitian yang telah ada.

Dalam perancangan simulator PLC ini perencangan hardware pertama yaitu merancang sebuah power supply yang digunakan sebagai tegangan input pada sebuah PLC atau yang nanatinya berfungsi untuk mengontrol gerbang logika dasar,traffic light dan konveyor

Perancangan Sofware dilakukan untuk mempermudah dalam perancangan simulator pada PLC dengan perancangan skema pada cx-programmer maka dengan mudah memprogramkan PLC sesuai dengan keinginan. Dengan mengontrol sensor sebagai input sedangkan traffic light,gerbang logika dasar dan konveyor sebagai ouput

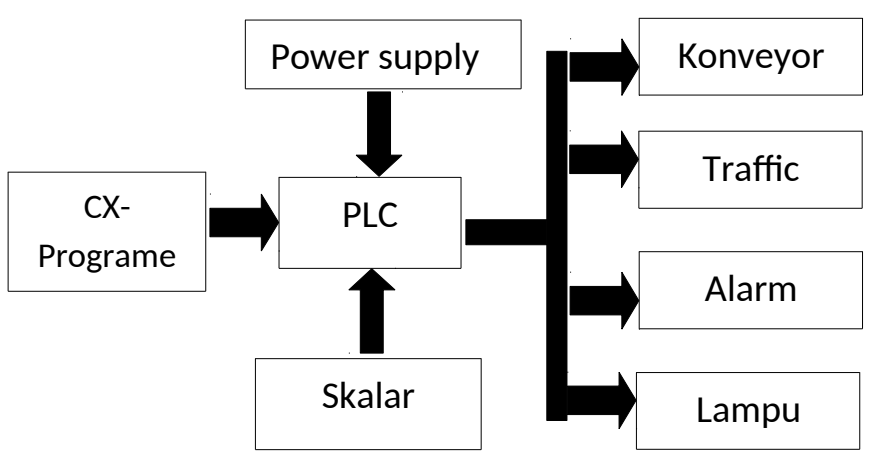

Gambar 1. Skema Perancangan Hardware Simulator PLC

\section{HASIL DAN PEMBAHASAN}

\section{A. Percobaan Gerbang Logika Dasar}

Percobaan dasar ini dilakukan dengan mengimplementasikan perintah-perintah dasar dalam pemrograman PLC dengan menggunakan diagram ladder.

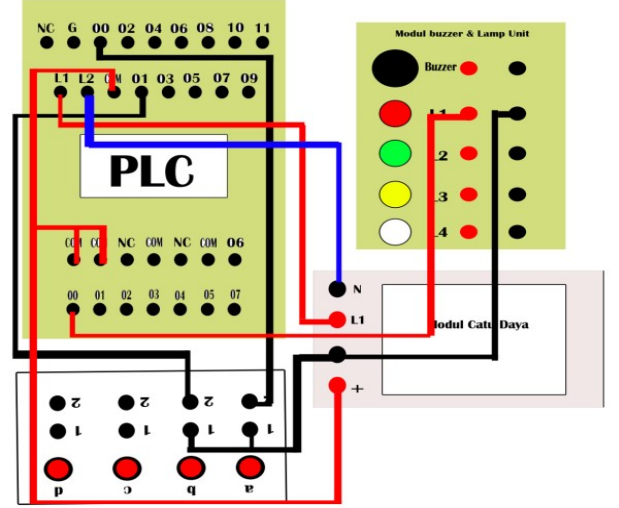

Gambar 2. Rangkaian Percobaan

1 Ledder diagram gerbang AND

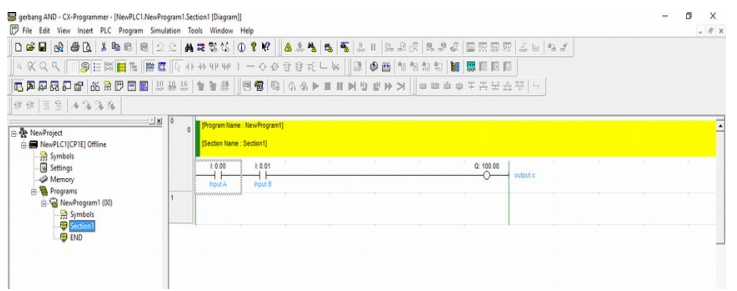

Gambar 3. Ladder Diagram Gerbang AND

Setelah di rangkai Transfer program ke PLC dalam keadaan online dan tekan saklar A dan B sedangkan C sebagai ouput atau lampu.

Hasil Percobaan

\begin{tabular}{|c|c|c|}
\hline $\mathbf{A}$ & $\mathbf{B}$ & $\mathbf{C}$ \\
\hline 0 & 0 & 0 \\
\hline 0 & 1 & 0 \\
\hline 1 & 0 & 0 \\
\hline 1 & 1 & 1 \\
\hline
\end{tabular}

2. Percobaan gerbang OR

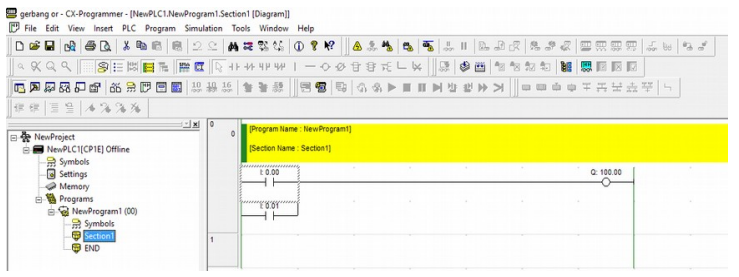

Gambar 4 Lader Diagram Gerbang Logika OR 
Setelah di rangkai Transfer program ke PLC dalam keadaan online dan tekan saklar A dan B sedangkan C sebagai ouput atau lampu

\section{Hasil percobaan}

\begin{tabular}{|c|c|c|}
\hline $\mathbf{A}$ & $\mathbf{B}$ & $\mathbf{C}$ \\
\hline 0 & 0 & 0 \\
\hline 0 & 1 & 1 \\
\hline 1 & 0 & 1 \\
\hline 1 & 1 & 1 \\
\hline
\end{tabular}

\section{Percobaan NOT}

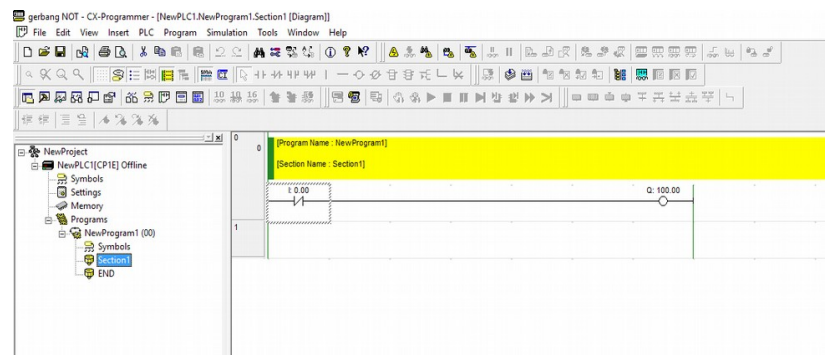

Gambar 5 Ladder Diagram Gerbang NOT

\section{Hasil Percobaan}

\begin{tabular}{|c|c|}
\hline $\mathbf{A}$ & $\mathbf{C}$ \\
\hline 0 & 1 \\
\hline 1 & 0 \\
\hline
\end{tabular}

\section{Percobaan XOR}

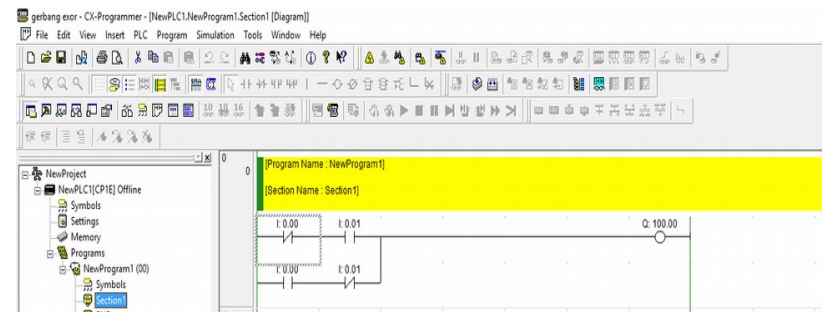

Gambar 6 Ladder Diagram Gerbang logika XOR

Setelah di rangkai Transfer program ke PLC dalam keadaan online dan tekan saklar A dan B sedangkan C sebagai ouput atau lampu

\section{Hasil percobaan}

\begin{tabular}{|c|c|c|}
\hline $\mathbf{A}$ & $\mathbf{B}$ & $\mathbf{C}$ \\
\hline 0 & 0 & 0 \\
\hline 0 & 1 & 1 \\
\hline 1 & 0 & 1 \\
\hline 1 & 1 & 0 \\
\hline
\end{tabular}

\section{Percobaan XNOR}

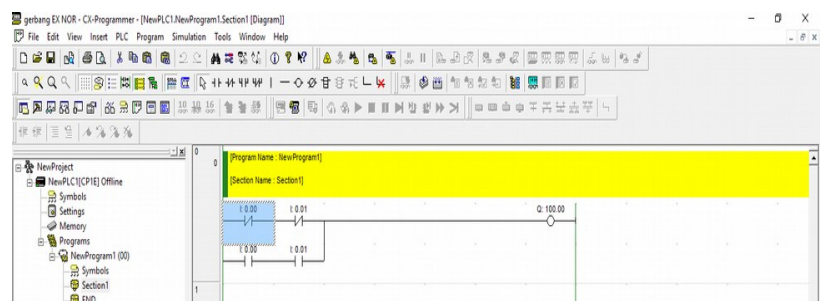

Gambar 7. Ladder Diagram Gerbang Logika EX - NOR

\section{Hasil Percobaan}

\begin{tabular}{|c|c|c|}
\hline $\mathbf{A}$ & $\mathbf{B}$ & $\mathbf{C}$ \\
\hline 0 & 0 & 1 \\
\hline 0 & 1 & 0 \\
\hline 1 & 0 & 0 \\
\hline 1 & 1 & 1 \\
\hline
\end{tabular}

\section{B. Percobaan Aplikasi PLC Sederhana}

Pada percobaan lampu cerdas cermat ini PLC digunakan sebagai kendali baik dalam proses penyalaan lampu maupun interlockbagi tiap peserta sehingga hanya yang paling cepaty yang mampu menyalakan lampu serta buzzer

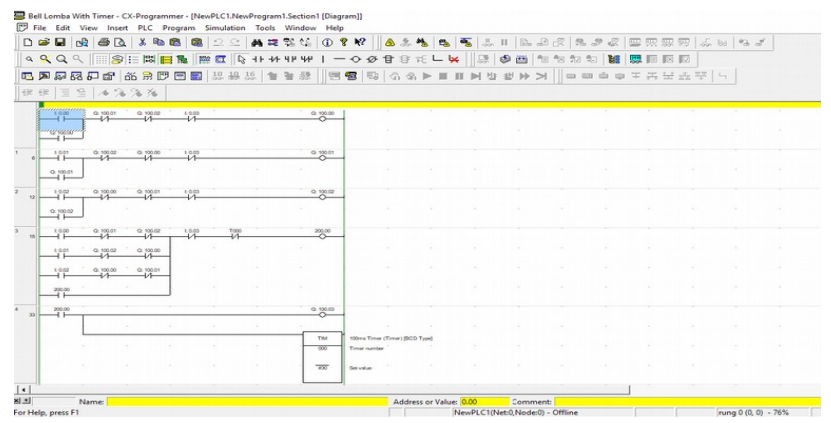

Gambar 8. Ladder Diagram Bell Lomba

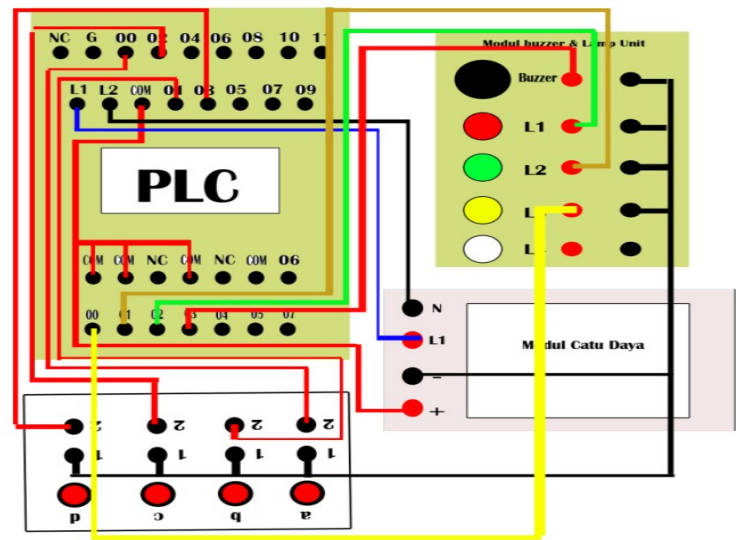

Gambar 9. Bentuk Rangkaian Bell Lomba 


\section{Hasil Percobaan}

Jika input 0.00 ditekan maka 100.00 akan hidup dan menyalakan lampu 1 dan 0.03 sebagi input mereset kembali dengan timer 3 detik sedangkan jika 0.01 berfungsi maka maka out 100.01 hidup sedangkan output 100.00 dan 100.02 tidak berfungsi karena terkunci sehingga hanya lampu 2 yang menyala sedangkan pada lampu 3 memiliki input 0.02 .

\section{Forward Reverse Control Motor}

Motor Listrik DC atau DC Motor adalah suatu perangkat yang mengubah energi listrik menjadi energi kinetik atau gerakan (motion). Motor DC ini juga dapat disebut sebagai Motor Arus Searah. Seperti namanya, DC Motor memiliki dua terminal dan memerlukan tegangan arus searah atau DC (Direct Current) untuk dapat menggerakannya.

Gambar rangkaian percobaan

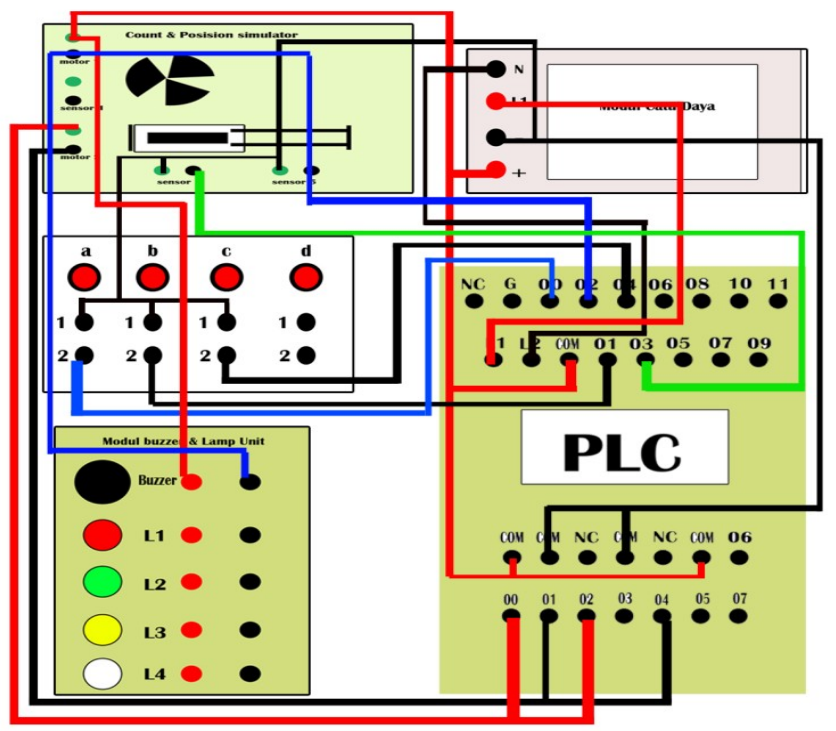

Gambar 10. Rangkaian Percobaan

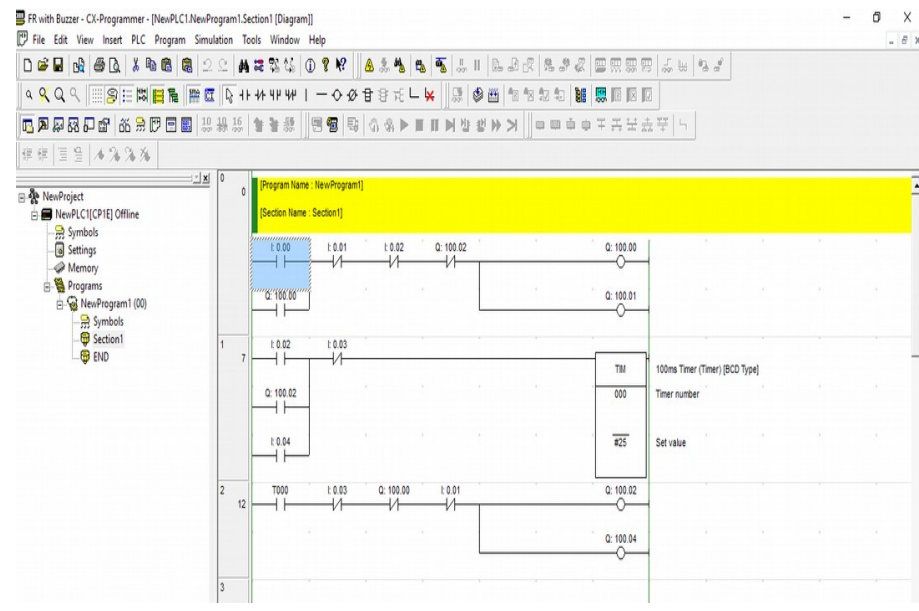

Gambar 11. Ladder Diagram

\section{Hasil Percobaan}

Jika 0.00 ditekan maka output 100.00 dan 100.01 akan berkerja dan memberikan putaran maju kedepan kepada motor dan pada T000 akan berfungsi secara otomatis selama 2.5 detik untuk kembali menghubungkan 100.02 dan 100.04 untuk membalikan putaran motor.

\section{Aplikasi PLC Lanjutan}

Traffic light adalah lampu yang digunakan untuk mengatur kelancaran lalu lintas di suatu persimpangan jalan dengan cara memberI kesempatan pengguna jalan dari masing -masing arah untuk berjalan secara bergantian. Karena fungsinya yang begitu penting maka lampu lalu lintas harus dapat dikendalikan atau dikontrol semudah dan seefisien mungkin guna memperlancar arus lalu lintas di suatu persimpangan jalan Seiring dengan perkembangan zaman yang juga disertai dengan perkembangan teknologi, jumlah kendaraan yang ada terus bertambah banyak sehingga lalu lintas di jalan juga semakin bertambah padat, akan tetapi hal tesebut tidak diikuti dengan perkembanagn infrastruktur yang ada. Perkembangan tersebut membawa dampak terhadap sist em lalu lintas yang ada yaitu dalam sistem pengaturan waktu penyalaan traffic light Sebagian besar pengendalian pewaktuan sistem traffic light yang ada pada saat ini masih menggunakan pewaktu yang sudah ter Hal itu menyebabkan operator tidak dapat mengubah-ubah waktu nyala lampu lalu lintas pada tiap-tiap arah setiap saat, untuk menyesuaikan kondisi jalan dan kepadatan kendaraan yang ada pada tiap ruas jalan Hal itu adalah sebagian kekurangan dari pengendalian traffic light pada saat ini.

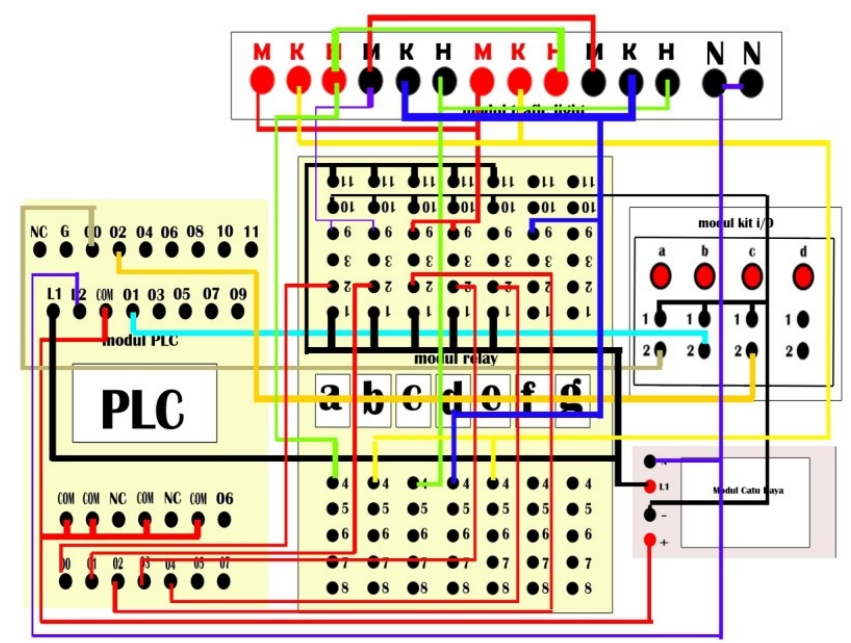

Gambsr 12. Rangkaian percobaan 


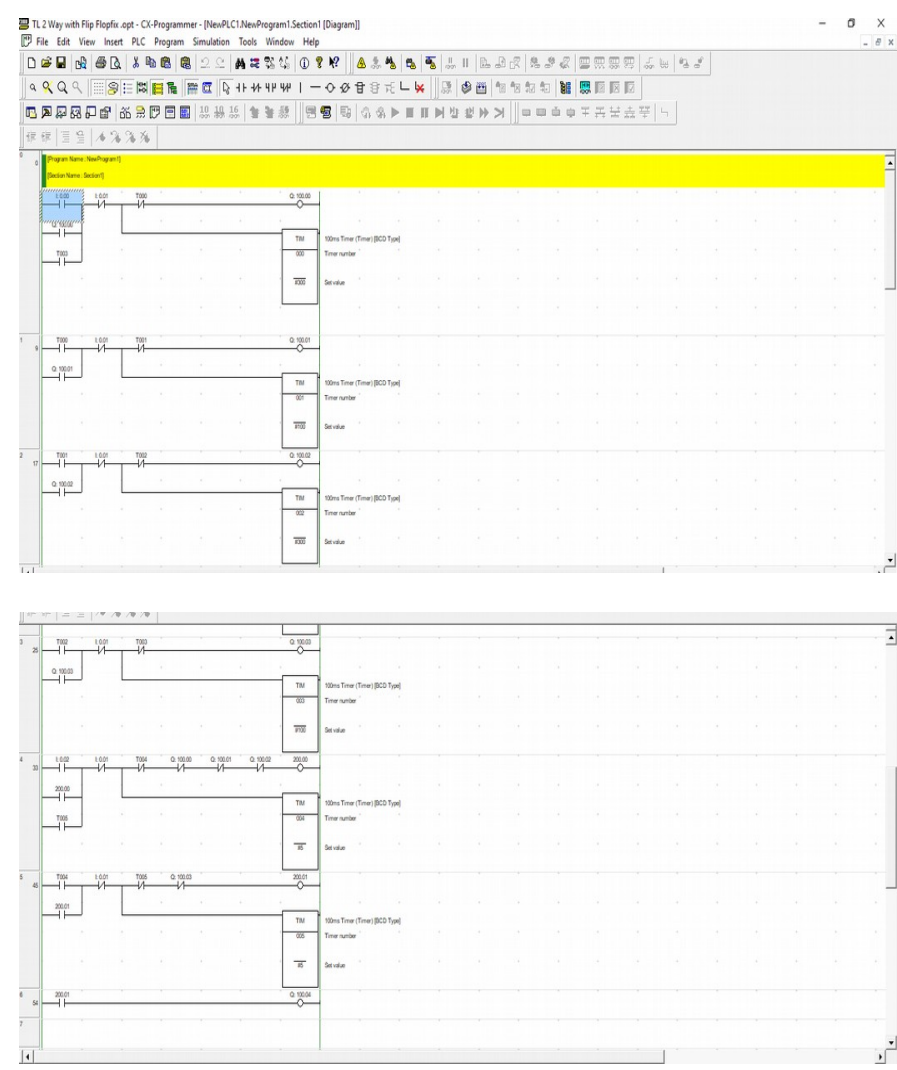

Gambar 13. Ladder Diagram percobaan

\section{Hasil Percobaan}

Saat 0.00 ditekan maka 100.00 akan berfungsi untuk menghidupkan relay A sebagai lampu merah dan hijau pada arah 1 dan 2 sedangkan timer selama 30 detik selesai maka 100.01 akan berkerja untuk lampu merah pada arah 1 tetap menyala sedangkan lampu hijau mati dan kuning menyala selama 10 detik untuk sedankgan pada 100.02 yaitu mehidupkan relay ke tiga dimana timer 30 detik untuk menghidupkan kebalikan dari 100.00.Pada input 0.02 berfungsi sebagai pengatur relay 5 dimana akan menghidupkan lampu kuning dalam bentuk flip - flop selama 0.5 detik dan jika input 0.01 ditekan maka akan memutuskan fungsi atau mematikan rangkaian.

\section{KESIMPULAN}

Berdasarkan pelaksaan perencanaan dan pembuatan simulator PLC untuk pratikumotomasi,maka disimpulkan bahwa:

1. Pembuatan PratikumPLC atau simulator PLC menggunakan PLC CP1E 20 DRA

2. Program yang digunakan adalah $\mathrm{CX}$ - Programer untuk mengatur input dan output pada PLC

3. Ada 4 percobaan yaitu pada percobaan gerbang logika dasar yaitu mampu menjalankan perintah NO, NC. Sedangkan pada pratikum PLC sederhana dengan tujuan mampu menjalankan perintah - perintah aplikasi PLC sederhana. Sedangkan pada percobaan tiga yaitu pada forward reverse control motor memiliki tujuan mampu membuat progrsm untuk kendali motor dan pada percobaan aplikasi PLC lanjutan memiliki pembelajaran tentang timer dan control pada PLC

\section{Saran}

Karena input dan output pada PLC terbatas maka diharapkan kedepan ada pengembangan untuk melanjutkan ke PLC yang lebih baik agar bias lebih memahami dan mampu mengoprasikan PLC secara luas.

\section{DAFTAR PUSTAKA}

[1] Bintoro, Jusuf, ; M Satria Pinandita, Edi Santoso, and Komang Oka. 2009. "Perancangan Simulator Plc Menggunakan Program Delphi." Perancangan Simulator PLC... (Jusuf Bintoro 1(1):12.

[2] Haritman, Erik et al. 2015. "Otomasi Industri Modular." 2013(August):2-6.

[3] irvan Indrawan, Erik Haritman, Dadang Lukman Hakim. 2013. "PEMBUATAN ANTARMUKA MESIN MANUSIA PADA MODUL LATIH PLC BERBASIS PERANGKAT LUNAK CX DESIGNER Irvan Indrawan , Erik Haritman , Dadang Lukman Hakim.” 12(2):97-106.

[4] Kurniawan, Muhammad Supono, Iwan Setiawan, and Aris Triwiyatno. 2012. "Perancangan Simulasi Supervisory Control and Data Acquisition Pada Prototipe Sistem Listrik Redundant." Ejournal.Undip.Ac.Id 14(1):7-12.

[5] omron. 2009. "The CP1E Programmable Controller: Economical , Easy to Use , and Efficient." The CP1E Programmable Controller: Economical, Easy to Use, and Efficient 60:1-50. 